\title{
Analysis of Employment Flow of Landscape Architecture Graduates in Agricultural Universities
}

\author{
Xia $\mathrm{Yao}^{1} \&$ Linchun $\mathrm{He}^{1}$ \\ ${ }^{1}$ Student Affairs Department, Sichuan Agricultural University, Chengdu, China \\ Correspondence: Xia Yao, Student Affairs Department, Sichuan Agricultural University, Chengdu, Sichuan, \\ China. E-mail: xiayao75@163.com
}

Received: August 6, 2012 Accepted: August 15, 2012 Online Published: September 26, 2012

doi:10.5539/ies.v5n6p117 URL: http://dx.doi.org/10.5539/ies.v5n6p117

\begin{abstract}
A statistical analysis of employment flow of landscape architecture graduates was conducted on the employment data of graduates major in landscape architecture in 2008 to 2011. The employment flow of graduates was to be admitted to graduate students, industrial direction and regional distribution, etc. Then, the features of talent flow and factors affecting the status quo were discussed, so as to offer theoretical foundation for scientific formation of relevant employment policies and provide guidance for graduates to pursue a job and select an employment.
\end{abstract}

Keywords: agricultural and forestry universities, graduates majoring in landscape architecture, employment

\section{Introduction}

In the past few years, with continuous improvement of market economical system and educational system reform in China, all the universities have enlarged their scale of recruitment of students and the number of graduates has been steadily on the increase ( $\mathrm{Li}, 2009)$. The issue of employment among graduates has become a focus of attention. Employment of university students affects allocation and distribution pattern of regional talent resources and plays a crucial role in running and development of the national social economy. During the economic transitional period and under the background of continuously deepened economic system and educational system reform, with imbalanced development of regional economy, implementation of the employment system of bilateral choice by university graduates and changes of university students' concepts of culture and employment, employment flow of university students has an obvious regional difference, which thus causes a multitude of influences upon sustainable and healthy development of the social economy and higher education and employment of university students (Zhang \& Fang, 2011). An analysis of the actual flow of employment region, city, industry, and employment unit of university graduates and their distribution situation not only reflects the status quo of economic and social development of all regions, but also reflects occupational choice tendency of graduates (Xu, 2010). Therefore, an analysis of the characteristics of employment flow of university graduates is of great significance to strengthen such functioning mechanism as regulation on the national policy and guidance on higher education and to realize harmonious development of employment of university students and regional economy, higher education and social demand. In the meantime, this also provides theoretical evidence for carrying out relevant employment policies in a scientific way and offers guidance for job seeking and occupational selection of graduates, so it has great theoretical value and realistic significance.

\section{Sample Data}

The sample data were the employment data of landscape architecture graduates in Sichuan Agricultural University from 2008 to 2011. The calculating method was specified by the Education Department of China, and statistical analysis of data was made according to the employment units on the employment agreement that students signed (Yao, 2012).

\section{Employment Flow of Landscape Architecture Graduates}

\subsection{Statistics of Admitted Graduate Students}

Facing the great employment pressure, whether pursuing advanced studies as graduate students or choosing direct employment was an important selection for graduates. With continuous expansion in the scale of recruitment of postgraduates in the past few years, a large number of graduates had taken part in the main forces 
of being admitted graduate students, which is becoming a major tendency for graduates to select. The following table was a statistic analysis of the situation of graduates major in landscape architecture in a university who were admitted to graduate students.

Table 1. Statistics of landscape architecture graduates being admitted to graduate students from 2008 to 2011

\begin{tabular}{lllll}
\hline Major & \multicolumn{4}{c}{ Year } \\
\cline { 2 - 5 } & 2008 & 2009 & 2010 & 2011 \\
\hline Cultivation of landscape plant & $14.95 \%$ & $23.20 \%$ & $23.20 \%$ & $19.53 \%$ \\
Landscape planning and design & $10.61 \%$ & $20.00 \%$ & - & $21.51 \%$ \\
Total & $13.29 \%$ & $22.29 \%$ & $23.20 \%$ & $20.41 \%$ \\
\hline
\end{tabular}

It was observed that the proportions of the population in the postgraduate entrance exam were increased from $13.29 \%$ in 2008 to $20.41 \%$ in 2011 , with an increscent of seven percentages. The proportion remained at a level above $20 \%$ from 2009 to 2011, and reached the highest in 2010, namely, $23.20 \%$. From the perspective of specialty, the proportion of graduates major in landscape planning and design kept a stable growth from 2008 to 2011, and also presented a benign increasing tendency, namely, 11 percentages.

\subsection{Analysis of Nature of Work Unit}

The intention of occupation selection of graduates could obtain from the statistics of the nature of work units. It could give useful information for the graduate employment guidance, and also provide certain references for students, who are still in university.

Table 2. Statistics of the nature of work unit of landscape architecture graduates from 2008 to 2011

\begin{tabular}{|c|c|c|c|c|c|}
\hline Year & Employment flow & $\begin{array}{l}\text { Cultivation of } \\
\text { landscape plant }\end{array}$ & $\begin{array}{l}\text { Landscape } \\
\text { planning and } \\
\text { design }\end{array}$ & $\begin{array}{l}\text { Landscape } \\
\text { technology } \\
\text { (junior college) }\end{array}$ & Average \\
\hline \multirow{5}{*}{2008} & $\begin{array}{l}\text { State organs and public } \\
\text { institutions }\end{array}$ & $8.41 \%$ & $4.55 \%$ & $7.07 \%$ & $6.91 \%$ \\
\hline & State-owned enterprise & $5.61 \%$ & $1.52 \%$ & $2.02 \%$ & $3.27 \%$ \\
\hline & Private enterprise & $68.22 \%$ & $59.09 \%$ & $64.65 \%$ & $64.00 \%$ \\
\hline & Grass-root project & $0.93 \%$ & $0.00 \%$ & $0.00 \%$ & $0.36 \%$ \\
\hline & Others & $16.82 \%$ & $34.85 \%$ & $26.26 \%$ & $24.36 \%$ \\
\hline \multirow{5}{*}{2009} & $\begin{array}{l}\text { State organs and public } \\
\text { institutions }\end{array}$ & $4.00 \%$ & $10.00 \%$ & - & $5.71 \%$ \\
\hline & State-owned enterprise & $1.60 \%$ & $2.00 \%$ & - & $1.71 \%$ \\
\hline & Private enterprise & $58.40 \%$ & $58.00 \%$ & - & $58.29 \%$ \\
\hline & Grass-root project & $2.40 \%$ & $0.00 \%$ & - & $1.71 \%$ \\
\hline & Others & $33.60 \%$ & $30.00 \%$ & - & $32.57 \%$ \\
\hline \multirow{5}{*}{2010} & $\begin{array}{l}\text { State organs and public } \\
\text { institutions }\end{array}$ & $5.15 \%$ & - & - & $5.15 \%$ \\
\hline & State-owned enterprise & $1.03 \%$ & - & - & $1.03 \%$ \\
\hline & Private enterprise & $61.34 \%$ & - & - & $61.34 \%$ \\
\hline & Grass-root project & $0.00 \%$ & - & - & $0.00 \%$ \\
\hline & Others & $32.47 \%$ & - & - & $32.47 \%$ \\
\hline \multirow{5}{*}{2011} & $\begin{array}{l}\text { State organs and public } \\
\text { institutions }\end{array}$ & $6.05 \%$ & $4.65 \%$ & - & $5.43 \%$ \\
\hline & State-owned enterprise & $2.79 \%$ & $2.91 \%$ & - & $2.84 \%$ \\
\hline & Private enterprise & $46.98 \%$ & $62.79 \%$ & - & $54.01 \%$ \\
\hline & Grass-root project & $3.26 \%$ & $2.91 \%$ & - & $3.10 \%$ \\
\hline & Others & $40.93 \%$ & $26.74 \%$ & 一 & $34.63 \%$ \\
\hline
\end{tabular}


In Table 2, it was clear that the proportion of graduates working in the state organs and public institutions had a tendency of decline, from $6.91 \%$ in 2008 to $1.48 \%$ in 2011. Considering the majors, there is no significant difference between the major of cultivation of landscape plant and the major of landscape planning and design. However, a comparison between undergraduates and junior college graduates shows that there is no significant superiority to undergraduates.

In table 2, it was observed that the proportion of graduates working in state-owned enterprises was relatively low, ranging from $1.03 \%$ to $3.27 \%$ in 2008 to 2011 . The reason was that there are a few state-owned enterprises of landscape architecture, providing the limited employment positions for graduates.

It was found that major graduates were employed by private enterprises (Table 2). More than $54 \%$ graduates worked in private enterprises, and the proportion in 2008 was the highest, with a proportion of $64.00 \%$. Private enterprises are flexible in management, and could offer graduates more developmental space, becoming a primary choice for graduates. Nevertheless, from data all over the years, as a result of fluctuation and influences of the real estate industry, demand on landscape architecture has been weakened. The proportion of graduates who choose to take a job in private enterprises present a tendency of decline, from $64 \%$ in 2008 to $54 \%$ in 2011 , with a decline of 10 percentages.

In Table 2, the proportion of graduates working in grass-root projects were increased from $0.36 \%$ in 2008 to $3.1 \%$ in 2011, increasing almost 2 percentages. Considering the majors, the proportion of graduates majoring in cultivation of landscape plant who choose to seek a job in grass-root projects is higher than that of graduates majoring in the major of landscape planning and design.

\subsection{Working Region}

Selection of working region is one of the major factors affecting graduates searching for and choosing an employment chance. Analyses of working region of graduated students could better grasp the tendency of searching for an occupation by graduate students, and could give graduates useful guidance to understand the employment direction and adapt to the competition market.

\subsubsection{Birth Places of Graduates}

The birth places of graduate students directly influence students on the selection of working region (Zhou, Yu, Jiang, \& Xu, 2012). An analysis of the birth places were conducted from 2008 to 2011 to find out the relationship with selection working region.

Table 3. Statistics of place of birth

\begin{tabular}{llllll}
\hline Year & $\begin{array}{l}\text { Place of } \\
\text { birth }\end{array}$ & $\begin{array}{l}\text { Cultivation of } \\
\text { landscape plant }\end{array}$ & $\begin{array}{l}\text { Landscape planning } \\
\text { and design }\end{array}$ & $\begin{array}{l}\text { Junior college of } \\
\text { landscape } \\
\text { technology }\end{array}$ & Total \\
\hline \multirow{2}{*}{2008} & Sichuan & $75.70 \%$ & $77.27 \%$ & $100.00 \%$ & $84.00 \%$ \\
& Chongqing & $11.21 \%$ & $10.61 \%$ & 0 & $6.91 \%$ \\
& Others & $13.08 \%$ & $12.12 \%$ & 0 & $8.00 \%$ \\
\multirow{2}{*}{2009} & Sichuan & $77.60 \%$ & $64.00 \%$ & - & $73.71 \%$ \\
& Chongqing & $12.80 \%$ & $16.00 \%$ & - & $13.71 \%$ \\
& Others & $9.60 \%$ & $20.00 \%$ & - & $12.57 \%$ \\
\multirow{2}{*}{2010} & Sichuan & $77.32 \%$ & - & - & $77.32 \%$ \\
& Chongqing & $7.22 \%$ & - & - & $7.22 \%$ \\
& Others & $15.46 \%$ & - & - & $15.46 \%$ \\
& Sichuan & $75.81 \%$ & $80.23 \%$ & - & $77.78 \%$ \\
& Chongqing & $11.16 \%$ & $10.47 \%$ & - & $10.85 \%$ \\
\hline
\end{tabular}

Generally speaking, it was found that the birth places of students were mainly concentrated within Sichuan, and more than $73 \%$ of graduates come from Sichuan. Graduates from Sichuane reached as much as $84 \%$ in 2008 and 
junior college graduates coming from Sichuan accounted for $100 \%$ of all. Following Sichuan, Chongqing is the second major place of birth of graduates. The proportion of graduates from Chongqing ranged from $6.91 \%$ to $13.71 \%$.

\subsubsection{Graduates Working in Sichuan and Chongqing}

From Table 4, it was found that more than $72 \%$ graduates chose to work in Sichuan from 2008 to 2011, and the highest proportion reached $89 \%$ in 2008 . However, it declined in recent years from $89 \%$ to $74 \%$. The proportion of graduates working in Chongqing was relatively low, respectively accounting for $2 \%$ or so and respectively $10.29 \%$ in 2009 and $6.72 \%$ in 2011, imbalanced during these years. The proportion of students who chose to seek a job outside Sichuan was on an obvious increase, from $10.91 \%$ to $25.84 \%$, with an increase of 15 percentages. Considering majors, students majoring in the cultivation of landscape plant were more than students majoring in the cultivation of landscape planning and design. And junior college students majoring in landscape technology all chose to work in Sichuan.

Comparison of Tables 3 and 4, it was found that graduates who are born in Sichuan would like to choose working chances in Sichuan. On the other hand, the tendency was changed from flow into Sichuan for working chances by students who are born outside Sichuan to flow outside Sichuan for working chances by students who are born in Sichuan. Almost 40\% graduates who are born in Chongqing would like to find working chances in other provinces outside Sichuan.

Table 4. Statistics of landscape architecture graduates working in Sichuan and Chongqing

\begin{tabular}{llllll}
\hline Year & Province & $\begin{array}{l}\text { Cultivation of } \\
\text { landscape } \\
\text { plant }\end{array}$ & $\begin{array}{l}\text { Landscape } \\
\text { planning } \\
\text { design }\end{array}$ & $\begin{array}{l}\text { Junior college of } \\
\text { and }\end{array}$ & $\begin{array}{l}\text { Total } \\
\text { technology }\end{array}$ \\
\hline \multirow{2}{*}{2008} & Sichuan & $85.05 \%$ & $83.33 \%$ & 1 & $89.09 \%$ \\
& Chongqing & $2.80 \%$ & $4.55 \%$ & 0 & $2.18 \%$ \\
& Others & $14.95 \%$ & $16.67 \%$ & 0 & $10.91 \%$ \\
& Sichuan & $73.60 \%$ & $70.00 \%$ & - & $72.57 \%$ \\
2009 & Chongqing & $9.60 \%$ & $12.00 \%$ & - & $10.29 \%$ \\
& Others & $26.40 \%$ & $30.00 \%$ & - & $27.43 \%$ \\
& Sichuan & $78.35 \%$ & - & - & $78.35 \%$ \\
& Chongqing & $1.03 \%$ & - & - & $1.03 \%$ \\
& Others & $21.65 \%$ & - & - & $21.65 \%$ \\
& Sichuan & $77.21 \%$ & $70.35 \%$ & - & $74.16 \%$ \\
& Chongqing & $6.05 \%$ & $7.56 \%$ & - & $6.72 \%$ \\
& Others & $22.79 \%$ & $29.65 \%$ & - & $25.84 \%$ \\
\hline
\end{tabular}

\subsubsection{Analysis of Concentrated Employment Places}

To better guide students in looking for working chances outside Sichuan and developing the employment market outside Sichuan, a statistics was conducted on 5 provinces other than Sichuan with concentrated employment. The following results were obtained (the proportion in Table 5 was the percentage of graduated students working in 5 provinces to the total graduated students working outside Sichuan).

Table 5. Five outside provinces (cities) with the most concentrated employment of landscape architecture

\begin{tabular}{llllllll}
\hline 2008 & & 2009 & & 2010 & & 2011 \\
\hline Chongqing & $22.22 \%$ & Chongqing & $37.50 \%$ & Beijing & $30.95 \%$ & Guangdong & $27.00 \%$ \\
Shanghai & $18.52 \%$ & Jiangsu & $14.58 \%$ & Guangdong & $23.81 \%$ & Chongqing & $26.00 \%$ \\
Hubei & $11.11 \%$ & Guangdong & $10.42 \%$ & Jiangsu & $9.52 \%$ & Beijing & $17.00 \%$ \\
Zhejiang & $11.11 \%$ & Beijing & $8.33 \%$ & Liaoning & $7.14 \%$ & Hubei & $4.00 \%$ \\
Guangdong & $7.41 \%$ & Fujian & $8.33 \%$ & Chongqing & $4.76 \%$ & Jiangsu & $4.00 \%$ \\
\hline
\end{tabular}


It can be found from Table 5, due to the cause of birth of place, Chongqing is a primary choice for graduates, and the proportion of graduates who chose to seek for a job in Chongqing was as high as $22 \%$ except in 2010. Then, Guangdong, Beijing, Jiangsu and Shanghai were also a place with concentrated employment of graduates. Since these provinces and cities are economically developed and mature in development of landscape architecture, and also large-sized landscape architecture enterprises, such as, Zonglv in Guangdong, Orient Scape in Beijing and Inland Scape in Guangdong as well as a multitude of real estate enterprises offer more employment opportunities for graduated students of landscape architecture, and there is an obvious tendency of flow among graduates.

To know well the situation of graduates who look for working chances in cities within Sichuan, a statistics on 5 cities within Sichuan with $t$ concentrated employment was conducted. In this statistics, the proportion Table 6 was the percentage of graduated students working in the 5 cities to the total population of graduated students looking for employment chances within Sichuan).

In Sichuan, Chengdu is the most favorite city for graduated students to find employment chances, with almost more than $50 \%$ graduated students who are working in Sichuan, and the proportion was as high as $69.69 \%$ in 2011. As the capital city of Sichuan, Chengdu is economically developed, with a lot of employment opportunities, and offers more chances for graduates, greatly favored by graduates.

Each year, approximate $20 \%$ graduated students were choose as postgraduate students, and majority graduates choose to stay at the same university, resulting in Yaan as the second largest city in Sichuan for graduates. Mianyang, Deyang, Yiban and Luzhou are also relatively economically developed and have relatively strong appeal.

Table 6. The 5 cities in Sichuan with concentrated employment of landscape architecture graduates

\begin{tabular}{lllllllllll}
\hline Year & The five cities within Sichuan with the most concentrated employment \\
\hline 2008 & Chengdu & $41.84 \%$ & Ya'an & $14.49 \%$ & Mianyang & $4.08 \%$ & Deyang & $2.86 \%$ & Luzhou & $2.86 \%$ \\
2009 & Chengdu & $66.61 \%$ & Ya'an & $21.57 \%$ & Mianyang & $1.57 \%$ & Deyang & $1.57 \%$ & Yibin & $0.79 \%$ \\
2010 & Chengdu & $58.29 \%$ & Ya'an & $27.24 \%$ & Neijiang & $1.97 \%$ & Mianyang & $1.97 \%$ & Yibin & $1.32 \%$ \\
2011 & Chengdu & $69.69 \%$ & Mianyang & $1.74 \%$ & Leshan & $1.05 \%$ & Luzhou & $1.05 \%$ & Ziyang & $1.05 \%$ \\
\hline
\end{tabular}

\section{Concluding Remarks}

Based on the above analysis of the employment flow of graduates of landscape architecture from 2008 to 2011, the following conclusions were obtained:

1) Employment and being admitted graduate students are two major choices for students (Yao, 2012). With expanding the scale of graduate students, increased requirements of employment positions on graduates' educational background, and had more development chances for graduates with higher educational background, more and more graduated students would like to be postgraduate students for further study. And in the current severe employment situation, more and more graduates had ideological pressure to avoid employment and to improve their own capacity, making many graduates to being admitted graduate students.

2) The analysis of the nature of work units of graduates indicated that the graduates had taken up an occupation through a multitude of channels, such as, civil servant, state organ and public institution, state-owned enterprise, non-public enterprises, national grass-root project and flexible employment. Their selection in terms of industry manifests the feature of diversification. At the same time, considering the flow direction of graduates majoring in landscape architecture in the past few years, due to its flexible management, more development chances and easy flow of talents, more graduates would like to seek for working chance in private enterprises (Zhao, Li, \&Chai, 2011). Graduates tend to take up an occupation in private enterprises with good economic benefit and high management efficiency. By contrast, demand of the state organ, public institution and state-owned enterprise on graduates majoring in landscape architecture is weakened, the number of graduates who take up an occupation in these fields' declines. The specific feature of the major of design in landscape architecture makes more graduates in grass-root project and flexible employment increase.

3) For working region, the majority of graduates majoring in landscape architecture would like to stay in Sichuan and tend to choose the central cities with developed economy and the surrounding urban agglomeration, including Chengdu, Mianyang and Luzhou, etc. Graduates who choose to take up an occupation outside Sichuan Province mainly concentrate in southeastern costal economic regions, which, meanwhile, are developed in 
landscape architecture and real estate industry, such as, Guangdong, Beijing, Jiangsu, Shanghai and so on.

Through the above analysis, it is indicated that graduates are affected by the following factors in their selection of the flow of employment. At first, economic factor is a primary one that affects the flow direction of graduates, which is mainly embodied in development prospect, economic development level and remuneration, etc (Zhao $\&$ Wei, 2010). Economically developed regions are extremely favored by graduates owing to their high income level, perfect infrastructure, and positive living, working and talent development environment (Ling, 2007). Then, system and government, to different extents, affect the flow direction of graduates' employment. The requirement of employment on educational background compels graduates to continue to pursue further study, resulting that more and more graduates would like to be as postgraduate students. The government has encouraged and supported graduates to take up an occupation in grass-root organizations and has promulgated a lot of preferential policies, this has appealed a large number of graduates to devote themselves to grass-root projects. Finally, in the process of searching for a job, with their change of the consciousness in employment selection, graduates focus more on realization of their self-value and self-sense of achievement and concentrate more on the development chances offered by the job positions.

\section{References}

Li, S, W. (2009). An Analysis of Employment Flow of Graduates and Countermeasures. Management Observer, 8.

Ling, S, B, (2007). Main Factors Affecting Undergraduate Employment and Countermeasures. Journal of East China Jiaotong University, 6.

Xu, X, D. (2010). Features and Analysis of Employment Flow Direction of University Graduates. Heilongjiang Researches on Higher Education, 6.

Yao, X. (2012, July). Study on Employment Flow of Agricultural Graduates in Agricultural and Forestry Universities. Asian Social Science, 8(8).

Zhang, J, F., \& Fang, L. (2011). An Analysis of Motives for Regional Differences in Employment Flow of University Students. Management Observer, 1 .

Zhao, Q, Q., \& Wei, F. (2010). An Analysis and Study of Influencing Factors for Regional Intention and Flow Direction of Employment of Graduates in Agricultural and Forestry Universities. Modern Business Trade Industry, 20.

Zhao, X, Y, Li, L., \& Chai, J. (2011). Analysis on the Employment Flows of Graduates from Agricultural Colleges and Universities and Unbalanced Development Reality of Local Economy. Journal of Anhui Agricultural Sciences, 39(14).

Zhou, Q, Yu, S, L, Zhang, Q., \& Xu, S, F. (2012). Survey Research on the Problem of Employment Flow among University Graduates. Daguan Weekly, 18. 